\title{
Cerebrovascular Injury Following Scorpion Sting and Snake Envenomation: A Case Series
}

\author{
Ajay Mishra, Aditya Binu, George Abraham, Harshad Vanjare, Tina George, \\ Ramya Iyadurai
}

\begin{abstract}
Background: Neurological complications following snake and scorpion bite are diverse. Literature regarding patterns of cerebrovascular injury (CVI) and outcomes among these patients is scarce. This is a descriptive study of the clinical profile, brain imaging findings, mechanisms of injury, vascular territory involvement and outcomes of CVI following scorpion and snake envenomation, in a tertiary care center in South India. Methodology: Patients with scorpion sting- and snake envenomation-related complications were retrospectively enrolled. Neuroimaging was performed on five patients with each envenomation, and they were found to have neurological involvement. On imaging, three patients were found to have a CVI. Clinical, radiological parameters and outcomes of these patients were studied. We also performed a review of the literature and analyzed the finding of all the cases. Result: In all, three patients each had evidence of CVI in imaging. An additional 32 reports of scorpion sting-related CVI and 35 reports of snake envenomation-related CVI were identified from the literature. There was a male predominance among these patients. Mean age of the patients with scorpion sting was 42.8 years as compared with 33 years for the patients with snake envenomation. Features of severe envenomation were present in all patients. Persistently depressed sensorium and new-onset focal neurological deficits were seen in $70 \%$ of all patients. Infarcts were seen in $88 \%$ of patients with snake envenomation and $53 \%$ of patients with a scorpion sting. Mortality was $28 \%$ among patients with a scorpion sting as compared with $8 \%$ with snake envenomation. Conclusion: Cerebrovascular injuries are uncommon neurological manifestations following scorpion and snake envenomation. These tend to occur in younger patients. Infarcts are more common than bleeds.
\end{abstract}

RÉSUMÉ: Des lésions cérébrovasculaires consécutives à des piqûres de scorpion et à des morsures de serpent : une série de cas. Contexte : Les complications d'ordre neurologique à la suite de piqûres de scorpion et de morsures de serpent sont diverses. À cet égard, rares sont les publications scientifiques portant sur les types de lésions cérébrovasculaires (LCV) induites par ces animaux et sur l'évolution de l'état de santé des patients qui en ont été victimes. Objectif: Dans un centre de soins tertiaires du sud de l'Inde, mener une étude descriptive tenant compte des aspects suivants à la suite de l'envenimation d'individus causée par un serpent ou un scorpion : le profil clinique des patients, les résultats d'une imagerie cérébrale, les mécanismes associés aux lésions cérébrales, le territoire vasculaire concerné et les conséquences de la ou des LCV encourues. Méthodologie: Des patients atteints de complications consécutives à une envenimation causée par un scorpion ou un serpent ont ainsi été recrutés de façon rétrospective. Cinq patients victimes chacun d'une envenimation ont présenté des complications neurologiques et ont bénéficié d'un examen de neuro-imagerie. Trois d'entre eux ont présenté une LCV lors d'un tel examen. Ont été étudiés les paramètres cliniques et radiologiques de ces patients de même que l'évolution de leur condition médicale. Nous avons aussi effectué une revue de littérature et analysé les résultats propres à chaque cas. Résultats: On l'a dit, trois patients ont montré chacun des signes de LCV lors d'un examen de neuro-imagerie. De plus, 32 cas de patients atteints de LCV attribuables à des piqûres de scorpion et 35 cas de patients atteints de LCV liés à une envenimation induite par des morsures de serpent ont été identifiés dans des publications scientifiques. La majorité de ces patients était de sexe masculin. L'âge moyen des patients victimes de piqûres de scorpion était de 42,8 ans alors que ceux victimes d'une envenimation causée par des morsures de serpent avaient en moyenne 33 ans. Les caractéristiques typiques d'une grave envenimation étaient présentes chez tous les patients. Un sensorium affaibli de façon durable et l'apparition de nouveaux déficits neurologiques ont été notés chez $70 \%$ des patients. Des infarctus ont aussi été observés chez $88 \%$ des patients victimes d'une envenimation induite par des morsures de serpent et chez $53 \%$ des patients ayant été piqués par un scorpion. Enfin, le taux de mortalité a été de $8 \%$ pour tous ces patients. Conclusions: On peut dire que des LCV constituent, à la suite de cas d'envenimation induite par un scorpion ou un serpent, des affections neurologiques inhabituelles. Ces dernières ont surtout tendance à survenir chez des patients plus jeunes. Notons de surcroît que des infarctus demeurent plus fréquents que des saignements.

Key words: Snake, Scorpion, Envenomation, Cerebrovasular injury

doi: $10.1017 / \operatorname{cjn} .2018 .328$

Can J Neurol Sci. 2018; 45: 669-674

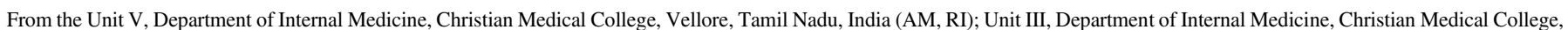

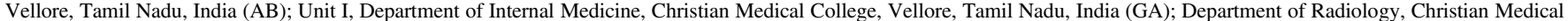

College, Vellore, Tamil Nadu, India (HV); Unit II, Department of Internal Medicine, Christian Medical College, Vellore, Tamil Nadu, India (TG)

Received December 14, 2017. Final Revisions Submitted May 2, 2018. Date of Acceptance June 24, 2018.

Correspondence to: A. Mishra, Unit V, Department of Internal Medicine, Christian Medical College, Vellore, Tamil Nadu, India. Email: ajaybalasore@gmail.com 


\section{INTRODUCTION}

Scorpion and snake envenomation are common causes of morbidity and mortality in the developing world. Manifestations following a snake bite and a scorpion sting are diverse. Neurological complications following snake and scorpion bite are protean. The sting of Mesobuthus tamulus (Indian red scorpion) and snakes of family Viperidae are known to cause cerebrovascular complications in rare cases. Literature regarding patterns of cerebrovascular injury (CVI) and outcomes among these patients is scarce. The objective of this study was to assess the demographic characteristics, clinical profile, brain imaging findings and details of vascular territory involvement among patients admitted with CVI following scorpion and snake envenomation, in a tertiary care center in South India. We also aimed to study the outcomes in terms of mortality in patients admitted with CVI following scorpion and snake envenomation.

\section{METHODOLOGY}

This study was conducted in Christian Medical College, Vellore, which is a 2700-bedded tertiary care health center in South India. This retrospective case series included patients seen in the General Medicine, Radiology Departments of Christian Medical College. All patients with a proven diagnosis of scorpion and snake envenomation were included in the study if they had (1) new-onset focal neurological deficit after the initial neurological manifestations subsided, (2) persistent declining in sensorium after 24 hours of admission despite adequate medical management and the (3) persistent presence of neurological deficits. If the patient fulfilled the inclusion criteria, neuroimaging was performed. All patients with scorpion envenomation between May, 2005 and August, 2016 (11 years) were retrospectively enrolled in the study. Similarly, patients with snake envenomation between May, 2014 and August, 2016 (2 years) were enrolled retro-

Table 1: Details of previously reported cases of cerebrovascular injury (CVI) in patients with snake envenomation and scorpion sting

\begin{tabular}{|c|c|c|}
\hline Variables & CVI following snake envenomation & CVI following scorpion sting \\
\hline Numbers & 35 & 32 \\
\hline Mean age (min-max) & $42.8(18-66)$ & $33(17-56)$ \\
\hline Gender (M:F) & $2.2(24 / 11)$ & $1.66(20 / 12)$ \\
\hline Hemiparesis & $11(31 \%)$ & $17(53 \%)$ \\
\hline Low sensorium only & $13(37 \%)$ & $9(28 \%)$ \\
\hline \multicolumn{3}{|l|}{ Imaging details } \\
\hline $\mathrm{CT}$ & $19(54 \%)$ & $26(81 \%)$ \\
\hline MRI & $16(46 \%)$ & $6(18 \%)$ \\
\hline \multicolumn{3}{|l|}{ Type of stroke } \\
\hline Infarct & $31(88 \%)$ & $17(53 \%)$ \\
\hline Hemorrhage & $2(6 \%)$ & $13(41 \%)$ \\
\hline Hemorrhagic infarcts & $2(6 \%)$ & $2(6 \%)$ \\
\hline Description of infarcts & & $(n=17)$ \\
\hline Single & $10(32 \%)$ & $9(53 \%)$ \\
\hline Multiple & $21(68 \%)$ & $8(47 \%)$ \\
\hline Unilateral & $16(51.5 \%)$ & $12(70.5 \%)$ \\
\hline Bilateral & $15(48.5 \%)$ & $5(24.5 \%)$ \\
\hline Description of hemorrhages & & $(n=13)$ \\
\hline Single & 1 & $12(92 \%)$ \\
\hline Multiple & 1 & $1(8 \%)$ \\
\hline Unilateral & 2 & $12(92 \%)$ \\
\hline Bilateral & 0 & $1(8 \%)$ \\
\hline \multicolumn{3}{|l|}{ Outcome } \\
\hline Hemorrhage & & 13 \\
\hline Alive & 2 & $8(61 \%)$ \\
\hline Dead & 0 & $5(39 \%)$ \\
\hline Infarct & & 17 \\
\hline Alive & $30(91 \%)$ & $13(76 \%)$ \\
\hline Dead & 3 & $4(24 \%)$ \\
\hline
\end{tabular}


spectively. Patients who did not have central nervous system (CNS) imaging were excluded from the study.

A total of 196 and 55 patients with snake envenomation and scorpion sting, respectively, were included in the study. Among these patients with snake and scorpion envenomation, five patients each satisfied inclusion criteria and were recruited for analysis. After recruitment, the details of demography, clinical features, laboratory features, imaging features, details of treatment and outcome were obtained from the hospital electronic medical records. The neuroimaging details on the pattern of injury, presence and characterization of infarcts were studied by an independent neuroradiologist who was unaware of the patient outcome. The details of the site, size, number and territory of infarcts were obtained by the radiologist. Data were entered in Microsoft Excel version 9, and data analysis was performed using statistical package for social science version 16 . The principal outcome that was studied was death. Mortality was ascertained at the time of discharge. We searched the standard database including MEDLINE and Google Scholar for articles mentioning cerebrovascular accident following snake and scorpion envenomation written in the English language after the year of 2000, including patients older than 16 years, providing appropriate CNS images. On reviewing the literature, we identified 32 and 29 cases of CVI following snake and scorpion envenomation, respectively, and analyzed the finding of all these cases together. In all, 35 age-matched controls with CVI and without envenomation were included in order to compare the differences in topography in CVI following snake/scorpion envenomation versus the age-matched controls.

\section{Results}

In all, $9 \%$ (5 of 55) and 2\% (5 of 196) of patients with scorpion sting and snake envenomation fulfilled the inclusion criteria and required neuroimaging. Among the five patients who fulfilled the inclusion criteria in both the groups, three had CVI as seen in imaging, respectively $(n=6)$. All six patients were male. The mean age of the patients with scorpion sting and snake envenomation was 40.6 and 36 years, respectively. Local pain, profuse sweating, palpitations and high blood pressure indicating severe toxemia were present in all the patients with scorpion sting. Similarly, all the three patients of Russell's viper envenomation showed the presence of local swelling, local and systemic bleeding and respiratory failure. While two patients had infarcts, one had a hemorrhage in either group. The mean time to onset of symptoms following the scorpion sting was 1.6 days, as compared with 4 days following snake bite. The mean duration of in-patient stay following the envenomation was 5 days for scorpion stings and 16 days for snake bites. All patients with scorpion sting were discharged in stable condition and two patients with snake envenomation were discharged in stable condition.

A total of 32 patients with scorpion sting and 35 patients with snake envenomation were included in the review, as shown in Table 1. Mean ages of patients with snake and scorpion envenomation were 43 and 33 years, respectively. There was a male preponderance among both the groups. Clinical features of depressed sensorium and hemiparesis were present in more than one-third of the patients with snake envenomation. Hemiparesis was present in more than half of the patients, and depressed sensorium was present in one-third of the patients with scorpion envenomation. CT brain was the most common neuroimaging performed for $54 \%$ and $81 \%$ of patients with snake and scorpion envenomation, respectively. Infarcts were the most common patterns of CVI and were seen in $88 \%$ and $53 \%$ with snake and scorpion envenomation, respectively. Among these, $68 \%$ of patients with snake envenomation and $47 \%$ of patients with scorpion sting had multiple infarcts. More than one infarct was

Table 2: Location of hemorrhage and infarcts following snake and scorpion envenomation and in age-matched patients with cerebrovascular injury (CVI) without envenomation

\begin{tabular}{|c|c|c|c|}
\hline Variables & CVI following snake envenomation & CVI following scorpion sting & CVI in age-matched controls without envenomation \\
\hline Hemorrhage (patient/number) & $2 / 2$ & $13 / 13$ & $7 / 7$ \\
\hline Capsuloganglionic & - & $4(30 \%)$ & $5(71 \%)$ \\
\hline Putamen & - & $3(23 \%)$ & $1(14.5 \%)$ \\
\hline Frontal & - & $3(23 \%)$ & $1(14.5 \%)$ \\
\hline Parieto-occipital & 1 & $1(7 \%)$ & - \\
\hline Cerebellar & 1 & $1(7 \%)$ & - \\
\hline Intraventricular & - & $1(7 \%)$ & - \\
\hline Infarcts (patient/number) & $31 / 43$ & $17 / 18$ & $26 / 40$ \\
\hline Capsuloganglionic & $5(16 \%)$ & $2(12 \%)$ & $10(25 \%)$ \\
\hline Frontal & $5(16 \%)$ & $2(12 \%)$ & $9(22.5 \%)$ \\
\hline Parieto-occipital & $19(61 \%)$ & $6(35 \%)$ & $11(27.5 \%)$ \\
\hline Cerebellar & $11(35 \%)$ & $4(23 \%)$ & $4(10 \%)$ \\
\hline Thalamus & $2(6 \%)$ & $2(12 \%)$ & $4(10 \%)$ \\
\hline Midbrain & $1(3 \%)$ & $2(12 \%)$ & - \\
\hline Intraventricular & - & - & - \\
\hline Others & - & - & $2(5 \%)$ \\
\hline
\end{tabular}


defined as multiple infarcts. In all, $48.5 \%$ of patients with snake envenomation and $28.5 \%$ of patients with scorpion sting had infarcts bilaterally. Among the controls, 26 (74\%) had infarcts, seven $(20 \%)$ had hemorrhages and two $(6 \%)$ had hemorrhagic infarcts. Among the controls, $13(50 \%)$ infarcts were multiple and six $(23 \%)$ were bilateral. Hemorrhages were more among patients with scorpion sting (41\% vs. $6 \%$ ). In all, $92 \%$ of patients with hemorrhage had single and unilateral involvement. Among the controls, all bleeds were single and unilateral. In the patients with scorpion sting, the most common sites of hemorrhage were capsuloganglionic region, similar to the controls, as shown in Table 2. The most common sites of infarcts following both the envenomations were parieto-occipital, cerebellar and capsuloganglionic and frontal region, respectively (Images 1 and 2). These were also similar to the topography of infarcts in age-matched controls (Table 2). Mortality in patients with cerebrovascular accidents following snake envenomation was $8 \%$, as compared with $28 \%$ in patients with scorpion envenomation and $5.7 \%$ in age-matched controls.

\section{DISCUSSION}

Envenomation is common in developing countries, with more than 50,000 and 2600 reports of mortality following snake and scorpion envenomations being reported per year. ${ }^{1,2}$ Along with the classical neurological manifestations of external ophthalmoplegia, ptosis and respiratory failure, these can also have multiple other systemic manifestations. An uncommon neurological manifestation following these envenomations is CVI. ${ }^{3,4}$ Reports of CVI are seen in $2.6 \%-4 \%$ of patients with snake and scorpion envenomations. ${ }^{5,6}$ Snakes of Viperidae family including Russel's viper, Indian green tree viper, Korean viper, species of other pit vipers

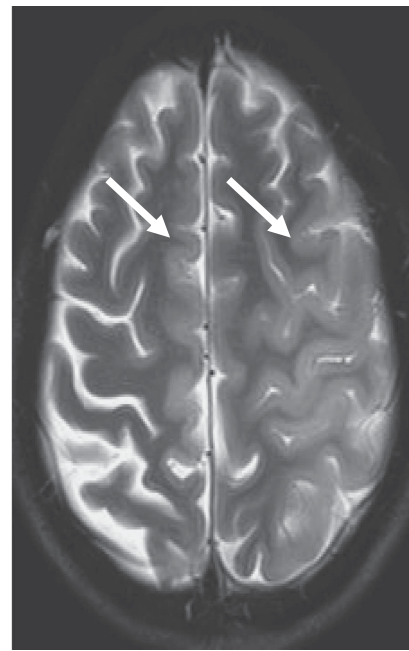

A1: T2W

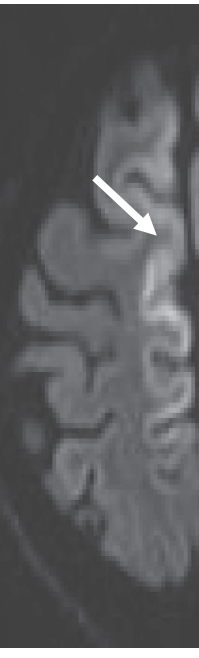

A2: DW

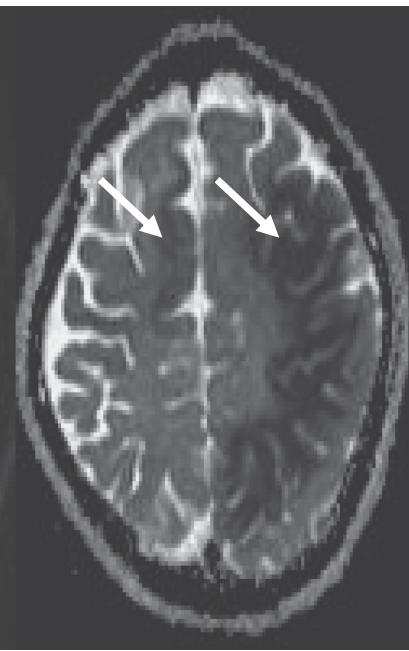

A3: ADC

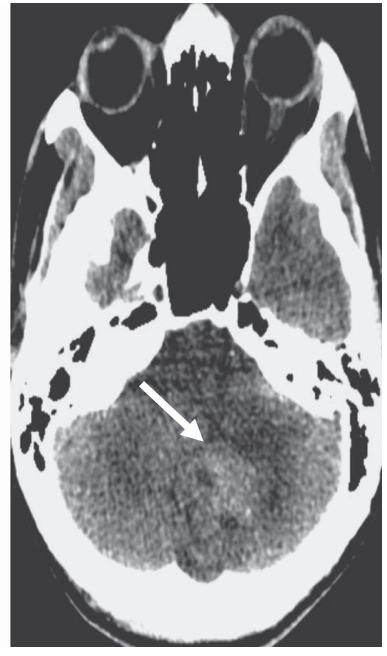

B: CT

Image 1: Image series (A) a 36-year-old man with snake bite. T2 weighted (T2W) shows swelling and hyperintensity in left middle cerebral artery and right anterior cerebral artery territory with associated diffusion restriction suggestive of acute infarct. (B) A 38-year-old man with snake bite. Non-contrast CT shows acute hematoma in the left cerebellar hemisphere with surrounding edema.

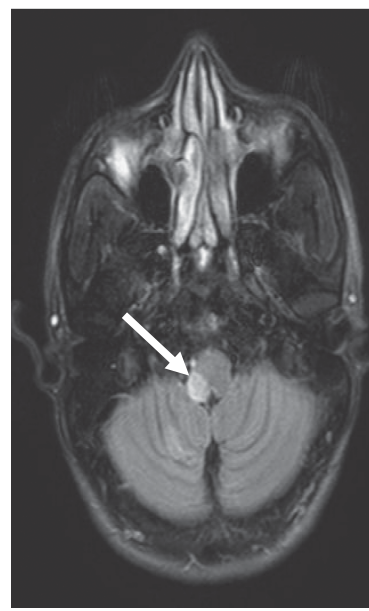

C1: T2 FLAIR

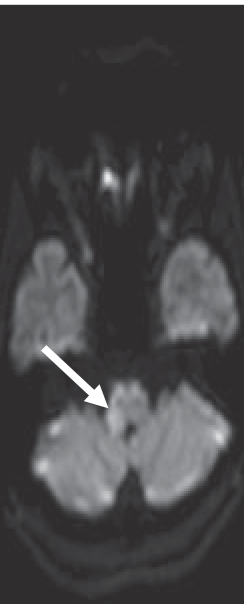

C2: DW

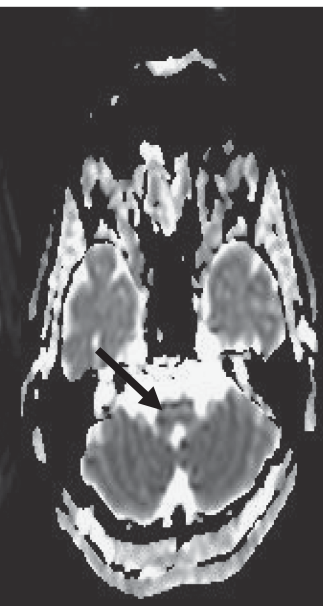

C3: ADC

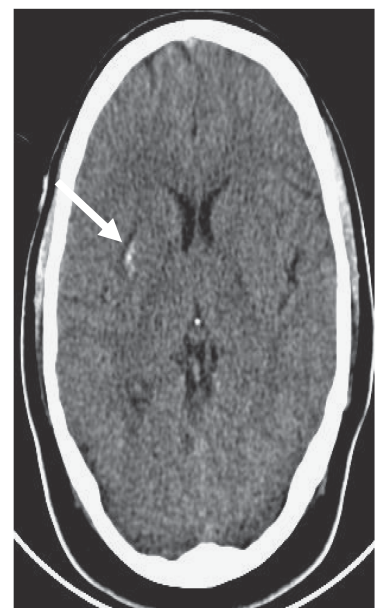

D:

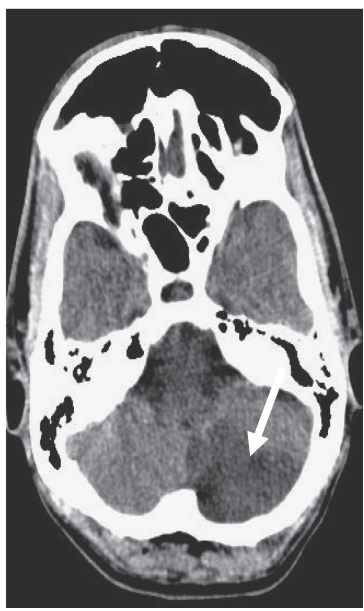

E: CT

Image 2: Image series $(C)$ a 45-year-old lady with scorpion sting. T2 flair image shows hyperintensity and expansion. Corresponding area shows diffusion restriction suggestive of acute right lateral medullary infarct. (D) A 29-year-old man with scorpion sting. Non-contrast CT brain show acute hemorrhage in the right putamen. (E) A 47-year-old man with scorpion sting. Non-contrast CT brain shows acute infarct in the left posterior inferior cerebellar artery territory. 
such as Cerastes, Bothrops and Crotalids are reported to cause complications related to cerebrovascular involvement. ${ }^{7-9}$ Among all the viper envenomations, reports of CVI are the highest among Russel's viper envenomation. ${ }^{10-12}$ Similarly, scorpions such as $M$. tamulus and Tityus serrulatus have been reported to cause cerebrovascular involvement. ${ }^{13-15}$ Various mechanisms have been postulated in causing vascular injury. Proteases and hemorragins cause direct damage to the vascular endothelium. Various toxins present in viper venom have both pro-coagulant and anti-coagulant effects. Toxins with pro-coagulant effect are cerastobin, cerastocytin, cerastotin, afaacytin and factor IVa. These toxins have properties of platelet aggregation, thrombin-like activity, procoagulant metalloproteases and activators of factor $\mathrm{V}$ and $\mathrm{X}$, which are instrumental in the activation of the coagulation cascade. The other mechanisms of vascular injury are toxin-induced vasospasm or toxic vasculitis, toxin-induced disseminated intravascular coagulation and hypoperfusion due to hypovolemia and hypotension. ${ }^{16-18}$ Mechanisms that have been postulated in patients with scorpion stings are (i) the presence of myocarditis leading to rhythm abnormality and embolic strokes, (ii) autonomic storm causing extremes of blood pressure, (iii) severe cerebral vessel vasospam owing to catecholamine excess and (iv) toxin-induced endothelial injury and vasculitis. ${ }^{19-21}$

At the time of initial presentation, these patients might have no neurological symptoms or depressed sensorium without any signs. $^{22,23}$ In a smaller subgroup of patients, cerebrovascular involvement should be considered in case of (1) persistence of depressed sensorium, initial neurological deficits and new-onset focal deficit. ${ }^{24-26}$ Persistently depressed sensorium is the most common neurological manifestation reported in the literature, as shown in Table 1. The other clinical manifestations that have been reported are new-onset generalized tonic-clonic seizures, varying motor weakness including hemiplegia, presence of visual field deficit and blindness, giddiness and dysarthria. ${ }^{27-29}$

Both CT and MRI have been used for confirmation of CVI among these patients. CT brain was performed for $75 \%$ of patients with scorpion sting and $53 \%$ of patients with snake envenomation in our review. Although CT is adequate to establish the diagnosis, an MRI with diffusion restriction is ideal in differentiating dilated venules and artifacts, which could be mistaken for infarcts. ${ }^{30}$ In both, infarcts and hemorrhages can be seen, with the former being common. Infarcts tend to be bilateral and multiple. Infarcts following both the envenomations were predominant in parietooccipital, cerebellar and capsuloganglionic regions, respectively (Images 1 and 2). Involvement of bilateral anterior cerebral artery, middle cerebral artery and the posterior cerebral artery is common, with the involvement of bilateral posterior cerebral artery reported to be most common. ${ }^{31-39}$ The uncommon neurological involvements that have been reported are the presence of thalamic infarct, lateral medullary syndrome and brainstem infarcts. $^{24,31,35,40}$ Hemorrhages tend to be unilateral and single. Common sites of hemorrhage are capsuloganglionic region, cortical and cerebellar, respectively (Table 2) (Images 1 and 2). Patients can also present with coexistent infarcts and hemorrhages, which was $6 \%$ in this review. ${ }^{11,32}$

All patients reviewed had features of severe envenomation at the time of admission. All these patients were treated medically and received blood products, anti-snake venom, an alpha-blocker (in case of scorpion sting) and optimal supportive care. Reported mortality of patients with cerebrovascular involvement following scorpion and snake envenomation is diverse, as compared with $8 \%$ following snake and $28 \%$ in scorpion envenomation. As most of these patients have evidence of venom-induced severe systemic toxicity such as shock, rhabdomyolysis, acute renal failure and coagulopathy, mortality among these patients cannot be solely attributed to the CVI. ${ }^{40,41}$ Future prospective studies with early diagnosis and prompt treatment can result in further reduction of mortality.

Most patients in this review had been recruited retrospectively, and hence detailed cardiac, autoimmune and thrombotic work-up had not been performed. No details were available on baseline National Institutes of Health Stroke Scale or Modified Rankin Scale of these patients. Similarly, we did not have details of validated functional neurological outcome including details on long-term follow-up. Variability in the severity of the toxidrome, delay in the presentation of the patient to a health care center and protocols of treatment could have had an impact on the events and outcome.

\section{CONCLUSIONS}

In conclusion, CVIs are uncommon neurological manifestations following scorpion and snake envenomation. These are more common in younger age group males without risk factors for stroke. This should be suspected in patients with persistently depressed sensorium and new-onset focal neurological deficits. In CNS imaging, infarcts are more common than bleeds. With optimal supportive medical care, mortality and morbidity are reduced. Further studies are required to understand the mechanism, risk factors and long-term neurological outcomes of these patients

\section{ACKNOWLEDGMENTS}

The authors would like to acknowledge Dr. Suniti Mani, Dr. Anu Anna George and Dr. Karthik G.

\section{Statement of Authorship}

All authors certify that they have participated sufficiently in the preparation of this manuscript.

\section{Disclosure}

AM, AB, GA, HV, TG and RI have nothing to disclose.

\section{REFERENCES}

1. Elkhayari M, Hachimi A, Ziadi A, Abdenasser Samkaoui M. Ischemic stroke following a scorpion sting. Rev Neurol (Paris). 2013;169(6-7):519-22.

2. Gawarammana I, Mendis S, Jeganathan K. Acute ischemic strokes due to bites by Daboia russelii in Sri Lanka - first authenticated case series. Toxicon. 2009;54(4):421-28

3. Lee BC, Hwang SH, Bae JC, Kwon SB. Brainstem infarction following Korean viper bite. Neurology. 2001;56(9):1244-45.

4. Nagaraja D, Verma A, Taly AB, Kumar MV, Jayakumar PN. Cerebrovascular disease in children. Acta Neurol Scand. 1994;90 (4):251-55.

5. Del Brutto OH, Del Brutto VJ. Scorpion stings: focus on cerebrovascular complications of envenoming. Int J Stroke. 2013;8 (4):E8.

6. Narang SK, Paleti S, Asad MA, Samina T. Acute ischemic infarct in the middle cerebral artery territory following a Russell's viper bite. Neurol India. 2009;57(4):479-80.

7. Mahale R, Mehta A, Javali M, Srinivasa R. A case of bilateral occipital lobe infarcts following Indian tree viper bite. J Stroke. 2014;16(3):205-07. 
8. Hoskote SS, Iyer VR, Kothari VM, Sanghvi DA. Bilateral anterior cerebral artery infarction following viper bite. J Assoc Physicians India. 2009;57:67-9.

9. Paul G, Paul BS, Puri S. Snake bite and stroke: our experience of two cases. Indian J Crit Care Med. 2014;18(4):257-58.

10. Subasinghe CJ, Sarathchandra C, Kandeepan T, Kulatunga A. Bilateral blindness following Russell's viper bite - a rare clinical presentation: a case report. J Med Case Rep. 2014;8:99.

11. Namal Rathnayaka RMMK, Kularatne SAM, Kumarasinghe KDM, Ranaweera J, Nishanthi Ranathunga PEA. Ischemic brain infarcts and intracranial haemorrhages following Russell's viper (Daboia russelii) bite in Sri Lanka. Toxicon. 2017;125:70-3.

12. Gouda S, Pandit V, Seshadri S, Valsalan R, Vikas M. Posterior circulation ischemic stroke following Russell's viper envenomation. Ann Indian Acad Neurol. 2011;14(4):301-03.

13. Eze C, Onwuekwe I, Ekenze O. Stroke as a rare consequence of scorpion sting and scorpion ingestion: a case report from South East Nigeria. Ann Trop Med Public Health. 2014;7(4):202-05.

14. Kochar DK, Singh P, Sharma BV, Saini G, Aggarwal P, Gauri LA. Scorpion envenomation causing hemiparesis. J Assoc Physicians India. 2002;50:606-07.

15. Jain MK, Indurkar M, Kastwar V, Malviya S. Myocarditis and multiple cerebral and cerebellar infarction following scorpion sting. J Assoc Physicians India. 2006;54:491-92.

16. Rebahi H, Nejmi H, Abouelhassan T, Hasni K, Samkaoui M-A. Severe envenomation by cerastes cerastes viper: an unusual mechanism of acute ischemic stroke. J Stroke Cerebrovasc Dis. 2014;23(1):169-72.

17. Merle H, Donnio A, Ayeboua L, Plumelle Y, Smadja D, Thomas L. Occipital infarction revealed by quadranopsia following snakebite by Bothrops lanceolatus. Am J Trop Med Hyg. 2005; 73(3):583-85.

18. Bush SP, Mooy GG, Phan TH. Catastrophic acute ischemic stroke after crotalidae polyvalent immune Fab (ovine)-treated rattlesnake envenomation. Wilderness Environ Med. 2014;25 (2): 198-203.

19. Sarkar S, Bhattacharya P, Paswan A. Cerebrovascular manifestations and alteration of coagulation profile in scorpion sting: a case series. Indian J Crit Care Med. 2008;12(1):15-7.

20. Malliboina S, Mahesh V, Agrawal A. Progressive hemiparesis following scorpion sting in a female with uncontrolled hypertension. West Afr J Radiol. 2014;21(2):85-6.

21. Udayakumar N, Rajendiran C, Srinivasan AV. Cerebrovascular manifestations in scorpion sting: a case series. Indian J Med Sci. 2006;60(6):241-44.

22. Gadwalkar SR, Bushan S, Pramod K, Gouda C, Kumar PM. Bilateral cerebellar infarction: a rare complication of scorpion sting. J Assoc Physicians India. 2006;54:581-83.

23. Cañas CA. Brainstem ischemic stroke after to Bothrops atrox snakebite. Toxicon. 2016;120 (Suppl C):124-27.
24. Ittyachen AM, Jose MB. Thalamic infarction following a Russell's viper bite. Southeast Asian J Trop Med Public Health. 2012;43 (5):1201-04.

25. Mosquera A, Idrovo LA, Tafur A, Del Brutto OH. Stroke following Bothrops spp. snakebite. Neurology. 2003;60(10):1577-80.

26. Sengupta S, Dhanapal P, Ravindran RD, Devi N. Cerebral blindness after scorpion sting. J Neuroophthalmol. 2009;29(2):154-55.

27. Raichur DV, Magar VS, Wari PK, Chandragouda DK. Hemiplegia and motor aphasia following scorpion sting. Indian J Pediatr, 68 (7):669-70.

28. Vale TC, Leite AF, da Hora PR, Coury MIF, da Silva RC, Teixeira AL. Bilateral posterior circulation stroke secondary to a crotalid envenomation: case report. Rev Soc Bras Med Trop. 2013;46(2):255-56.

29. Gupta S, Tewari AK, Nair V. Cerebellar infarct with neurogenic pulmonary edema following viper bite. J Neurosci Rural Pract. 2012;3(1):74-6.

30. Mishra AK, Arvind VH, Muliyil D, et al. Cerebrovascular injury in cryptococcal meningitis. Int J Stroke. 2018;13:57-65.

31. Kumar RM, Babu RP, Agrawal A. Multiple infarctions involving cerebral and cerebellar hemispheres following viper bite. J Med Soc. 2015;29:51-3.

32. Boviatsis EJ, Kouyialis AT, Papatheodorou G, Gavra M, Korfias S, Sakas DE. Multiple hemorrhagic brain infarcts after viper envenomation. Am J Trop Med Hyg. 2003;68(2):253-57.

33. Krishna PV, Ahmed S, Reddy KVN. Ischemic stroke consequent to snake bite. J NTR Univ Health Sci. 2017;6(3):192.

34. Godpower MC. Cerebellar infarct with neurogenic pulmonary edema following viper bite. J Neurosci Rural Pract. 2012;3(1):4-5.

35. Fernández-Bouzas A, Morales-Reséndiz ML, Llamas-Ibarra F, Martínez-López M, Ballesteros-Maresma A. Brain infarcts due to scorpion stings in children: MRI. Neuroradiology. 2000;42 (2): 118-20.

36. Dube S, Sharma VK, Dubey TN, Gouda NB, Shrivastava V. Fatal intracerebral haemorrhage following scorpion sting. J Indian Med Assoc. 2011;109(3):194-95.

37. Bucaretchi F, Capitani EMD, Fernandes CB, Santos TM, Zamilute IAG, Hyslop S. Fatal ischemic stroke following Tityus serrulatus scorpion sting in a patient with essential thrombocythemia. Clin Toxicol. 2016;54(9):867-70.

38. Tiwari SK, Gupta GB, Gupta SR, Mishra SN, Pradhan PK. Fatal stroke following scorpion bite. J Assoc Physicians India. 1988;36 (3):225-6.

39. Thacker AK, Lal R, Misra M. Scorpion bite and multiple cerebral infarcts. Neurol India. 2002;50(1):100-02.

40. Thomas VV, George T, Mishra AK, Mannam P, Ramya I. Lateral medullary syndrome after a scorpion sting. J Family Med Prim Care. 2017;6:155-57.

41. Chandrashekar D, Anikethana GV, Kalinga BE. Viper bite presenting as acute ischemic stroke. Int J Sci Res. 2014;11 (3):319-21. 